\title{
Dynamic indexing and clustering of government strategies to mitigate Covid-19
}

\author{
Jani Kinnunen, Irina Georgescu, Zahra Hosseini, Ane-Mari Androniceanu
}

\begin{abstract}
A B S T R A C T
Objective: The objective of the article is to identify the reference group of countries with similar Covid strategies and other groups with their performance success, and to construct a composite Covid Mitigation Index for comparative purposes, thus, implying how to redesign the strategic policies.

Research Design \& Methods: Gaussian Mixture Modelling and Factor Analysis: the main design is quantitative, using Gaussian Mixture Modelling to find the optimal number of country clusters, and Factor Analysis with Principal Axis Factoring (FA-PAF) to build a composite index of governmental policies. Data includes eight mitigation policy variables and three supporting economic policy variables. Data are aggregated to form three periods and the cluster changes are identified by Gaussian Mixture Modelling. Then, the Covid Mitigation Index (CMI) is constructed by FA-PAF to obtain a comparative measure over the periods and the country clusters. The results were obtained by means of $R$ studio and SPSS.

Findings: The dynamic clustering leads to a decreasing number of clusters from nine clusters in the first period (January-February 2020), four clusters in the second period (March-April 2020), and two clusters in the third period (May-June 2020). In the first period, China (with $\mathrm{CMI}=48$ ) took serious actions forming its own cluster, while 11 other countries (with $\mathrm{CMI}>10$ ), e.g., early affected European countries such as Italy and Spain and large Asian countries such India and Indonesia, took moderate actions. In the second period all cluster averages were greater than China's in the first period, i.e., most world countries were dedicated to fight Covid-19. In Europe, Italy, San Marino and France showed the highest CMI values, similarly to Iraq and Palestine in the Middle East, Peru and Honduras in the Latin America, and China, India and Indonesia in Asia. In the third period, cluster averages showed even tighter policies even though 42 countries had lower CMI values than previously.

Implications \& Recommendations: The approach provided a big picture for decision makers both in business and in governments. The key idea was to reveal reference groups of countries which help governmental actors to design and adapt their strategies over time by learning by their own experience and the results of the better performing clusters. It was suggested that a multi-criteria approach accounting for individual government's preferences over health and economy is used along with the presented approach.
\end{abstract}

Contribution \& Value Added: Clustering with Gaussian Mixture Models and factor analysis based on Principal Axis Factoring for composite-index building were used. The methods are well-established, but they were applied in a novel way dynamically over time and for the composite CMI. CMI was built on two factors which identified the structure of mitigation policies and economic policies. The development of governmental polices over the first cycle of Covid-19 pandemic was described.

$\begin{array}{ll}\text { Article type: } & \text { research article } \\ \text { Keywords: } & \text { clustering; composite index; pandemic; public policy; Covid-19 mitigation }\end{array}$

JEL codes: $\quad$ Z38, C82

Received: 31 January $2021 \quad$ Revised: 8 March $2021 \quad$ Accepted: 10 March 2021

\section{Suggested citation:}

Kinnunen, J., Georgescu, I., Hosseini, Z., \& Androniceanu, A.-M. (2021). Dynamic indexing and clustering of government strategies to mitigate Covid-19. Entrepreneurial Business and Economics Review, 9(2), 7-20. https://doi.org/10.15678/EBER.2021.090201 


\section{INTRODUCTION}

The global Covid-19 pandemic has affected various aspects of life including health, economics, tourism etc. related to both private behaviour and governmental actions. While finding a solution to this epidemic requires a global consensus, governments are facing specific challenges in designing and implementing their policy decisions.

The objective of the study is to identify the reference group of countries with similar Covid strategies and other groups with their performance success and to construct a composite Covid Mitigation Index (CMI) for comparative purposes, thus, implying how governments can redesign the strategic policies. The two research questions are formulated as follows.

RQ1: Which clusters of countries may be identified during the period January-June 2020 and how do the clusters develop over time?

RQ2: How can the pandemic mitigation policies be compared using a composite index over the identified clusters and time?

To tackle the research questions, firstly, an approach to compare Covid-mitigation policies of world countries is presented. The Gaussian Mixture Modelling (GMM) (Bouveyron et al., 2019) is used to obtain clusters of countries roughly over the first cycle of the current pandemic, January-June 2020. The research period is divided into three subperiods and the changes in country clusters are identified. Secondly, a composite index called Covid Mitigation Index (CMI) is constructed for all countries and each period, and the cluster averages of CMIs are used for comparative purposes. This is done by factor analysis with principal axis factoring, FA-PAF, which is a new approach, to the best knowledge of the authors, in constructing a composite index. It is an extension of a more traditional composite indexing by Principal Component Analysis (PCA). FA-PAF is better in detecting the structure, in this case, the factor of economic policies is separated from the factor of restriction-focused mitigation policies.

The originality of this study consists in applying GMM clustering and constructing the composite Covid-Mitigation Index by means of FA-PAF, rather than using the most common PCA approach. The proposed composite index has both a scientific value and a practical utility, since it can serve to the management of government policies during the Covid-19 crisis. So far, no such an index has been found in the literature.

The rest of the article is structured as follows. In the next section, relevant literature is reviewed. Then, the methods and the data used are described. We chose Gaussian Mixture Modelling as a soft clustering technique, in which each object belongs to each cluster with a membership degree. The objects generated by a Gaussian distribution are grouped in clusters. As a clustering method, GMM is more flexible than K-means clustering. While in K-means clustering the clusters are assumed to be round-shaped, characterised by the mean, in GMM clustering this assumption is less restrictive. In GMM clustering, the mean and the standard deviation characterise the clusters' shape (McLachlan \& Peel, 2000). In the analysis part, firstly, GMM is dynamically applied over the three consecutive periods to obtain changing country clusters for each two-month period. Secondly, a composite index is built using FA-PAF and the index is used to interpret the dynamic clusters. Thirdly, the results are summarised by describing the development of the situation of the world countries over the three sub-periods. Finally, the article concludes and some future research opportunities and practical ways to use the presented approach together with county-specific preferences of health and economy are suggested.

\section{LITERATURE REVIEW}

Cheng et al. (2020) classified the policymakers' strategies against Covid-19 with respect to different dimensions: a) the action type of strategy (e.g., quarantine); b) the level of action (e.g., national); c) the target (e.g., national or provincial); d) the human or material target (e.g., travel or mask); e) the direction (e.g., inbound or outbound); f) the mechanism of action; g) enforcement; h) enforcer; and i) the timing of action. While governments and policymakers are focusing to find the best strategies to handle the tough health and economic situations, the result of a large survey covering 58 countries 
demonstrated that majority of respondents were not satisfied with their governments' actions. The authors draw the attention of policymakers to reduce people's worry and depression and improve their mental health (Fetzer et al., 2020).

Due to the importance of collecting and interpreting data to understand and find the better-implemented strategies to deal with the pandemic, many studies have started to collect data from available resources. Hale et al. (2020a) used the data collected in real time from the Oxford Covid-19 Government Response Tracker (OxCGRT) to understand the responses of governments of different countries during the pandemic. The results indicated that the governmental responses became stronger over time and variations of actions among the countries were reduced. Stronger mitigation policies lead to greater social and economic impacts. Several programmes have been implemented on national and transnational levels. For example, Androniceanu (2020) discusses the main EU's objectives and instruments applied to reduce the social and economic impact of the Covid-19 crisis, including a EUR 100 billion SURE programme to help with workers' income and to support businesses to stay active. Indeed, clustering the data helps policy makers and managers reduce the impacts of Covid-19 (Androniceanu \& Marton, 2021). Accordingly, many researchers have attempted to cluster data and defined the algorithm based on that (Zarikas et al., 2020, Kinnunen \& Georgescu, 2020, Kinnunen et al., 2020, Rahman et al., 2020, James \& Menzies, 2020, Andersen et al., 2020; Kosach et al.2020).

Zarikas et al. (2020) made an analysis which resulted in clustering countries with respect to active cases, active cases per population and per area based on the epidemiological data of John Hopkins Coronavirus Resource Center. Some other researchers proposed algorithms through an intelligent fusion of healthcare and simulated mobility data, and their results demonstrated the significance of dynamic clustering for reducing lockdown coverage, economic loss, and military unit deployment (Rahman et al., 2020; Androniceanu et al. 2020a; 2020b). By analysing the number of cases and deaths in each country, James and Menzies (2020) found similar clusters of countries and determined the most effective strategies. They suggested to implement easier access to early testing to manage the spread of the disease and emphasized the importance of timeliness of various lockdowns rather than their severity.

The activity of many corporations worldwide has been jeopardised due to Covid-19 implications. Sierra et al. (2020) discuss successfully implemented strategies in a metal working Mexican company, by computing a new index of organisational prevalence. Sawangchai et al. (2020) use an e-questionnaire on entrepreneurial Thai university students and prove that the quality of e-services and e-information positively influence e-learning education for entrepreneurs in the context of Covid-19 (Wach \& Bilan, 2021; Nowiński et al., 2020). Marona and Tomal (2020) discuss the implications of Covid-19 on the real estate market in Krakow. Real estate agents have been found to have intensified the use of digital technologies in running their businesses. Mollenkopf et al. (2020) examined how the supply chain ecosystem ensured the customers' well-being in the context of the Covid-19 pandemic. Pantano et al. (2020) propose some recommendations for retailers to follow in order to adapt to the increasing demand of consumers during Covid-19 pandemic. These recommendations would be: new dynamic capabilities, a more important role played by retailers as essential workers, digital communication and a focus on consumers' well-being.

The research by Davulis et al. (2021) evaluates some psychological support measures that could be taken to the Lithuanian population and entrepreneurs in order to improve their psychological well-being worsened by the Covid-19 pandemic. Such measures could include: an increase in the number of workplaces in medical institutions and schools, a raise in salaries, training for psychologists, campaigns to inform the population on available counselling. Haleem et al. (2020) briefly present the healthcare, economic and social daily effects of Covid-19. Following a study on Pakistani voluntary participants, Zandi et al. (2020) find out that doctors' exposure to Covid-19 patients positively impacts their job stress. Moyo (2020) tests three hypotheses on how the risk of Covid-19 influences poor working conditions and employee disengagement on an adult population from Matabeleland South Region, Zimbabwe.

Due to the rather original approach of this study, we did not form strong explicit hypotheses, but based on our preliminary findings in Kinnunen et al. (2020), the plausibility of a similar approach was demonstrated based on dynamic clustering with composite index building for the European Union countries over a three-month period and different techniques than in this study. We may expect a 
decreasing number of identified clusters, as well as stronger and increasing government policies over time based on Hale et al. (2020a) and Kinnunen et al. (2020).

\section{RESEARCH METHODOLOGY}

The data is collected for 179 world countries for the period from January to June 2020 from Oxford COVID-19 Government Response Tracker (Hale et al., 2020b) on governmental responses to the current pandemic. Table 1 presents the variables, their descriptions and coding in the original daily data.

Table 1. Used data variables and their coding

\begin{tabular}{|c|c|c|}
\hline ID & Description & Coding of daily active policies \\
\hline $\mathrm{C} 1$ & $\begin{array}{l}\text { Record closings of schools and univer- } \\
\text { sities }\end{array}$ & $\begin{array}{l}0 \text { - no measures, } 1 \text { - recommended, } 2 \text { - required, } 3 \text {-required } \\
\text { closing all levels }\end{array}$ \\
\hline $\mathrm{C} 2$ & Record closings of workplaces & as above \\
\hline $\mathrm{C} 3$ & Cancellation of public events & 0 - no measures, 1 -recommended, 2 -required \\
\hline C4 & Restrictions on gatherings & $\begin{array}{l}0-\text { no measures, } 1 \text { - restrictions on gatherings }>1000 \text { people, } \\
2 \text { - between } 101-1000,3 \text { - between } 11-100,4-10 \text { or less }\end{array}$ \\
\hline $\mathrm{C} 5$ & Record closing of public transport & 0 - no measures, 1 - recommended, 2 - required \\
\hline C6 & Stay at home requirements & $\begin{array}{l}0-\text { no measures, } 1 \text { - recommended, } 2 \text { - required with some } \\
\text { exceptions, } 3 \text { - required with minimal exceptions }\end{array}$ \\
\hline $\mathrm{C7}$ & $\begin{array}{l}\text { Record restrictions on internal move- } \\
\text { ment between cities/regions }\end{array}$ & $\begin{array}{l}0-\text { no measures, } 1 \text { - recommended not to travel, } 2 \text { - required } \\
\text { not to travel }\end{array}$ \\
\hline $\mathrm{C} 8$ & $\begin{array}{l}\text { Record restrictions on international } \\
\text { travel of foreigners }\end{array}$ & $\begin{array}{l}0 \text { - no measures, } 2 \text { - quarantine at some arrivals, } 3 \text { - banned } \\
\text { some arrivals, } 4 \text { - total border closure }\end{array}$ \\
\hline E1 & $\begin{array}{l}\text { Income support (direct cash pay- } \\
\text { ments) for households }\end{array}$ & $\begin{array}{l}0-\text { no support, } 1 \text { - less than } 50 \% \text { of lost salary, } 2-50 \% \text { or } \\
\text { more of lost salary }\end{array}$ \\
\hline E2 & $\begin{array}{l}\text { Debt/contract relief (frozen financial } \\
\text { obligations, banning evictions, etc.) }\end{array}$ & $\begin{array}{l}0-\text { no debt/contract relief, } 1-\text { narrow relief, specific to one } \\
\text { kind of contract, } 2 \text { - broad debt/contract relief }\end{array}$ \\
\hline E3 & $\begin{array}{l}\text { Announced economic stimuli (spend- } \\
\text { ing or tax cuts) }\end{array}$ & USD monetary value \\
\hline
\end{tabular}

Source: own processing adapted from Hale et al. (2020b).

The daily data is summed up to obtain weekly, monthly, and finally two-month aggregated values. This gives us three periods of data: (1) January-February 2020, (2) March-April 2020, and (3) May-June 2020.

The most frequent clustering technique is K-means algorithm, which assigns each object to exactly one cluster, uses Euclidean distance and produces circular clusters. In K-means algorithm each cluster centre is described using a single point in the feature space. If clusters overlap in the feature space, it is hard to know which assignment is right since both are plausible. We will apply Gaussian Mixture Models. GMM is a clustering technique based on probability density estimation using Gaussian mixture models and a procedure called Expectation-Maximisation (EM) to fit the model parameters (Bouveyron et al., 2019). GMM is an extension of K-means algorithm in which clusters are modelled with Gaussian distributions. We have the cluster mean and covariance that describes their ellipsoidal shape.

Next, the model is fitted by maximising the likelihood of the observed data using EM. The EM algorithm will assign the objects to each cluster with a probability. After clustering one creates a probability model for the data. Based on this model one can sample new examples similarly to the initially measured data. Also based on this model one can compare two data collections like the training and test sets to see if they differ.

GMM is a probability distribution model. One begins with several mixture components indexed by c. Each mixture component is described by a Gaussian mixture distribution: the mean $\mu_{c}$ the variance/covariance $\sigma_{c}$ and the size of the distribution $\pi_{c}$. The joint probability distribution is defined by the weighted average of the individual components: $p(c)=\sum_{c} \pi_{c} N\left(x ; \mu_{c}, \sigma_{c}\right)$. The Gaussian $N()$ is defined by $\mu_{c}$ and $\sigma_{c}$. 
The GMM models are classified into three categories, according to the combinations of the constraints: spherical, diagonal, and ellipsoidal (Celeux \& Govaert, 1995).

The EM algorithm has two iterative steps:

- the expectation step, where the expected probabilities of points to clusters are determined, starting from the current model parameters; and

- the maximisation step, where the optimal model parameters of each mixture model are determined considering the probabilities as weights.

To construct the composite Covid-Mitigation Index (CMI) we apply Factor Analysis using Principal Axis Factoring, FA-PAF (Fabrigar et al., 1999) instead of the more typical approach based on principal components of PCA (Joliffe, 2002) to reduce the number of variables. The difference between the two approaches is that PCA assumes that there is no unique variance and, thus, the total variance of the used data is equal to common variance, i.e., shared by all the data, while FA-PAF allows the total variance to be composed of both the common variance and the portion of the total variance which is not shared, but is unique, i.e., variable-specific or errors coming from measurement. The FA-PAF approach is typically more realistic. New variables, factors, are constructed from the original data variables as linear combinations of original data. IBM SPSS V20 is used to reveal the data structure by extracting two factors from the rotated correlation matrix.

\section{RESULTS AND DISCUSSION}

\section{Clustering by Gaussian Mixture Modelling}

In the analysis, we have three periods in line with Androniceanu et al. (2020), but we will show the detailed analysis only for the middle period of March-April 2020. The similar analysis was conducted for the other two periods and we will only show the resulting clusters for these other periods.

Table 2 shows the three best clustering models according to Bayesian Information Criterion (BIC) using the expectation-maximising (EM) algorithm.

Table 2. BIC values of the top-three clustering models

\begin{tabular}{|c|c|c|}
\hline VVE,4 & VVE,3 & VVE,5 \\
\hline-3997.348 & -4018.504 & -4025.652 \\
\hline
\end{tabular}

Source: own calculations in R-studio.

The optimal model uses the VVE (ellipsoidal, equal orientation) covariance parameters with four clusters. The optimal model is selected according to several information criteria parameters, such as Akaike Information Criterion (AIC), Bayesian Information Criterion (BIC), Integrated Complete-data Likelihood (ICL) likelihood ratio (Biernacki et al., 2000). The highest BIC (-3997.348) is given by the model VVE with four clusters as seen in Table 3. It means there are four clusters with variable volume, variable shape, equal orientation and ellipsoidal distribution. Cluster 1 has 30, cluster 2 has eight, cluster 3 has 53, and cluster 4 has 15 countries.

Table 3. The optimal VVE model with four components

\begin{tabular}{|c|c|c|c|c|}
\hline log-likelihood & $\mathbf{n}$ & $\mathbf{d f}$ & BIC & ICL \\
\hline-1619.995 & 179 & 146 & -3997.348 & -4017.392 \\
\hline
\end{tabular}

Source: own calculations in R-studio.

Figure 1 shows how GMM compares nine models to obtain the optimal number of clusters (horizontal axis) based on the BIC criterion (vertical axis).

GMMs have a semi-parametric model-based approach to density estimation. GMMs are able to accurately approximate any given probability distribution. The estimated mixing probabilities $\left(\pi_{k}\right)$ for each member distribution in the mixture model are: $\pi_{1}=0.18098992, \pi_{2}=0.45644627, \pi_{3}=$ $0.27799583, \pi_{4}=0.08456799$. 


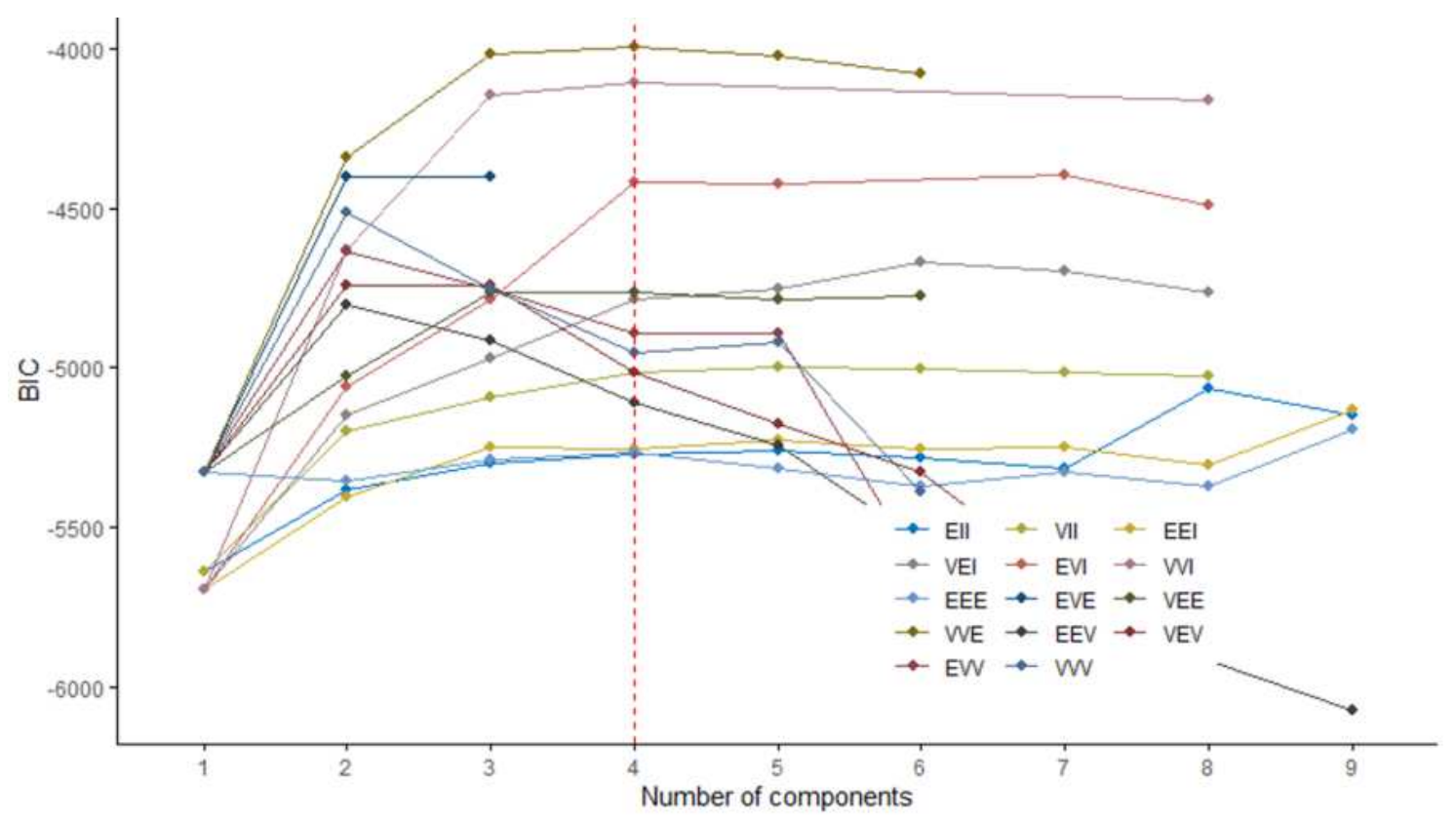

Figure 1. BIC scores for cluster models with profiles and the optimal number of clusters Source: own calculations in R-studio.

The four clusters of period March-April 2020 are shown in Figure 2. After conducting GMM also for the two other periods, which is not shown here, we will see later also the other two periods and compare them dynamically.

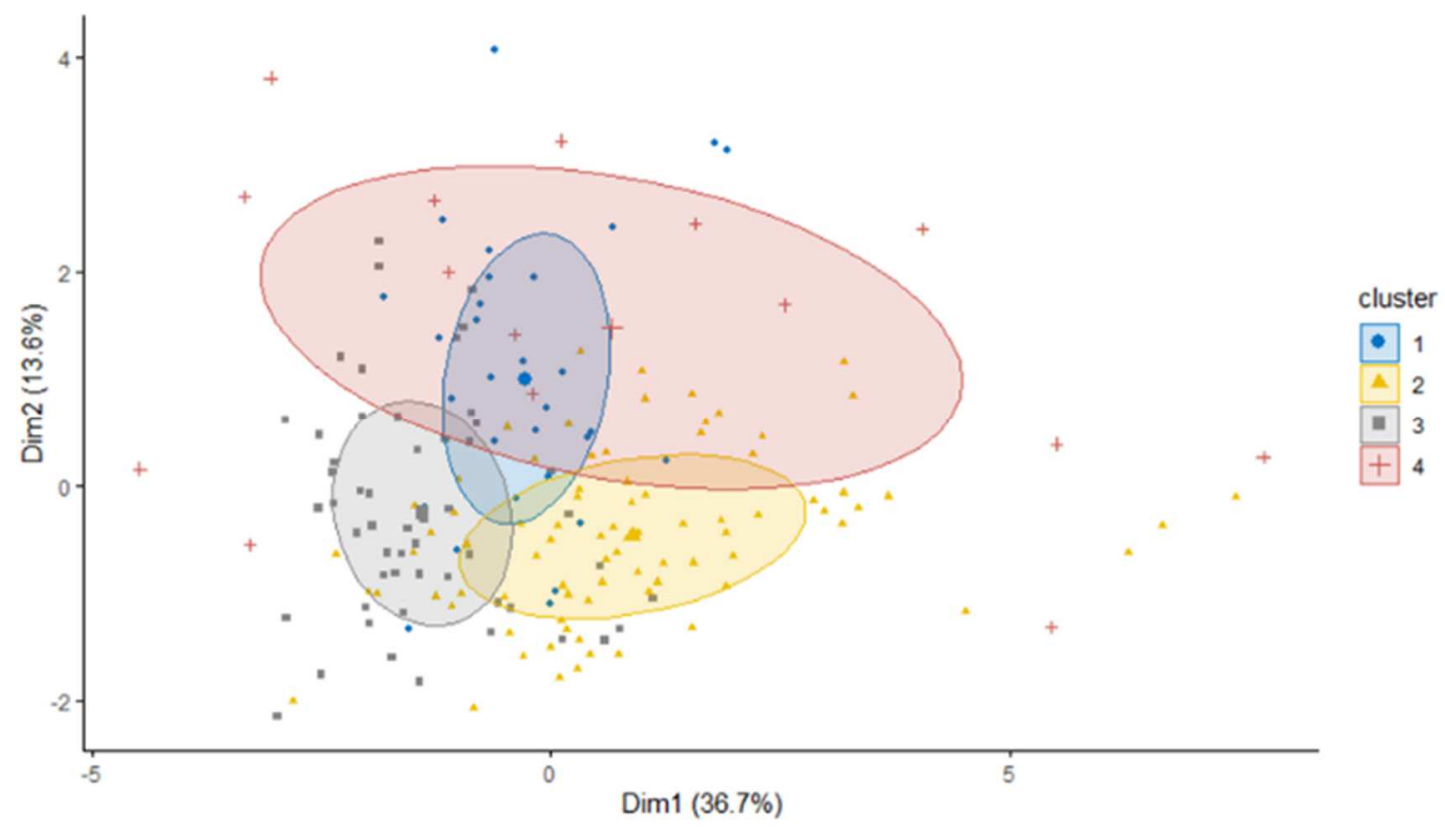

Figure 2. Elliptical four clusters of 179 countries in March-April 2020 Source: own calculations in R-studio.

\section{Indexing by Principal Axis Factoring}

Factor Analysis is applied with Principal Axis Factoring as the estimation method (FA-PAF). Figure 3 shows the screeplot (on left) of eigenvalues and the number of factors. One criterion typically used with PCA is to choose components/factors, which have eigenvalue $>1$. The two first factors are seen in Table 4 to have eigenvalues $>1$. Thus, we extract two factors. On the right side of Figure 3 , the 
rotated factor plot is seen in the space of the two factors. It is seen that mitigation-policy variables C1C8 (blue dots) are clustered on the same sector with the largest values of factor 2, while economic policies E1-E2 (green dots) have the highest values of factor 1, while E3 is close to the origin.
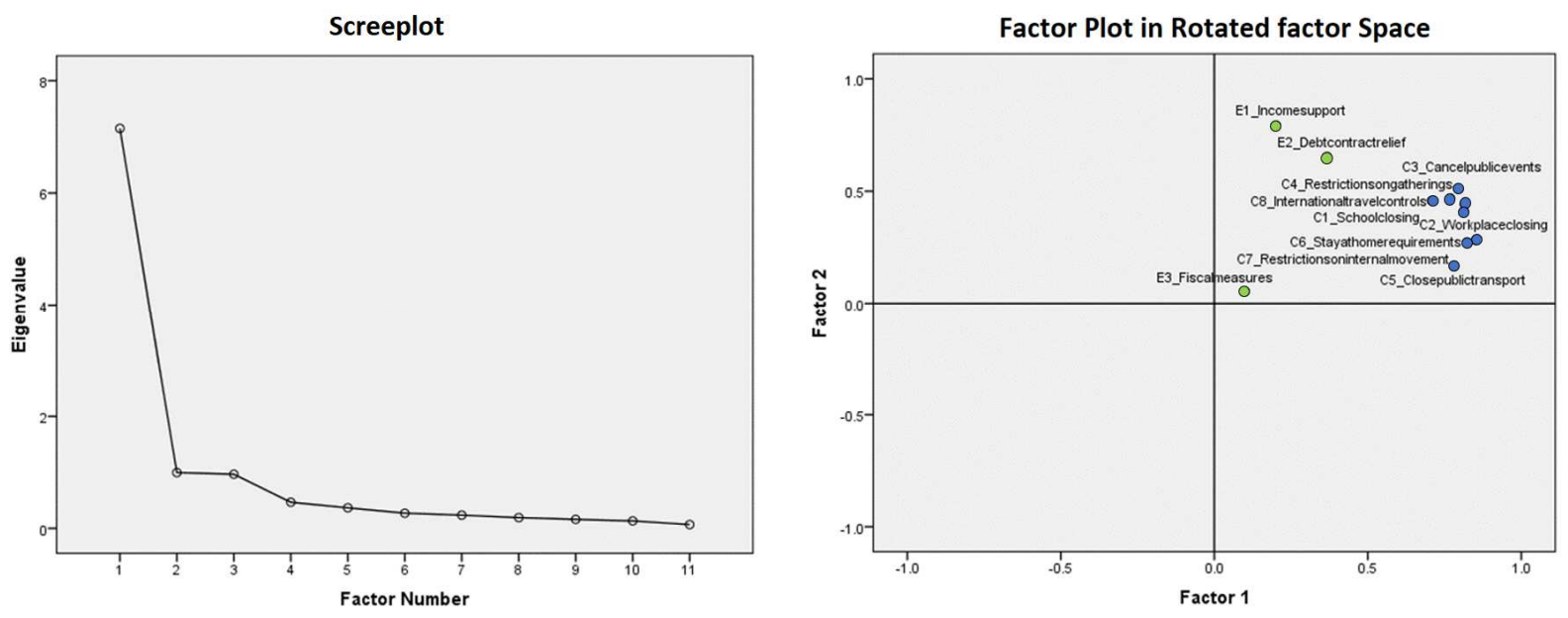

Figure 3. Screeplot (left) and the factor plot (right) Source: own analysis with SPSS.

Table 4 shows the 11 factors which together explain $100 \%$ of the total variance, but we will retain only the first two factors, which together explain $68.58 \%$ of the total variance. This fact is confirmed by Kaiser criterion, according to which we retain the first two factors whose eigenvalues $>1$.

Table 4. Total variance explained by each factor and cumulatively

\begin{tabular}{|c|r|r|r|r|r|r|}
\hline \multirow{2}{*}{ Factor } & \multicolumn{5}{|c|}{ Initial Eigenvalues } & \multicolumn{3}{c|}{ Rotation Sums of Squared Loadings } \\
\cline { 2 - 7 } & Total & \% of Variance & Cumulative \% & Total & \% of Variance & Cumulative \% \\
\hline F1 & 7.15 & 65.01 & 65.01 & 5.24 & $\mathbf{4 7 . 6 7}$ & 47.67 \\
\hline F2 & 1.00 & 9.05 & 74.06 & 2.30 & $\mathbf{2 0 . 9 1}$ & $\mathbf{6 8 . 5 8}$ \\
\hline F3 & 0.97 & 8.78 & 82.84 & & & \\
\hline F4 & 0.47 & 4.23 & 87.08 & & & \\
\hline F5 & 0.37 & 3.34 & 90.41 & & & \\
\hline F6 & 0.27 & 2.46 & 92.87 & & & \\
\hline F7 & 0.24 & 2.14 & 95.01 & & & \\
\hline F8 & 0.19 & 1.74 & 96.74 & & & \\
\hline F9 & 0.16 & 1.45 & 98.19 & & & \\
\hline F10 & 0.13 & 1.20 & 99.39 & & & \\
\hline F11 & 0.07 & 0.61 & 100.00 & & & \\
\hline
\end{tabular}

Source: own calculations in SPSS.

Table 4 shows that factor 1 explained $47.67 \%$ of the total variance and factor $220.91 \%$. These can be further used to obtain weights for factor 1 and factor 2 as their share of the total variance explained by the two (68.58\%). Thus, to obtain CMI, we weigh factor 1 by $47.67 \% / 68.58 \%$ and factor 2 by $20.91 \% / 68.58 \%$ :

$$
\begin{gathered}
C M I=0.592 * C 7+0.572 * C 6+0.566 * C 1+0.565 * C 2+0.552 * C 3+0.542 \\
* C 5+0.535 * C 4+0.535 * C 8+0.242 * E 1+0.199 * E 2
\end{gathered}
$$

The rotated correlation matrix of Table 5 is used to construct the composite index. We will only consider the bold factor loadings which are greater than 0.5 in their absolute value. The variables are ordered by the factor loadings, i.e., factor 1 is correlated most strongly with Restrictions on internal movement (C7) and then in decreasing order, but relatively strongly with all variables C1-C8 except the economic policy variables E1-E3. Factor 2 is most correlated with Income support (E1) 
and strongly also with Debt/contract relief (E2), while interestingly Fiscal measures (E3) will be the only dropped variable as its correlation with both factors is negligible.

Based on factor loadings of Table 5, we need a middle step to formulate the two factors as:

$$
\begin{gathered}
F 1=0.851 * C 7+0.823 * C 6+0.814 * C 1+0.813 * C 2+0.794 * C 3+0.780 \\
* C 5+0.769 * C 4+0.708 * C 8 \\
F 2=0.793 * E 1+0.654 * E 2
\end{gathered}
$$

Table 5. Rotated correlation matrix

\begin{tabular}{|l|c|c|}
\hline \multicolumn{1}{|c|}{ Variables } & Factor $\mathbf{1}$ & Factor $\mathbf{2}$ \\
\hline C7 - Restrictions on internal movement & $\mathbf{0 . 8 5}$ & 0.28 \\
\hline C6 - Stay at home requirements & $\mathbf{0 . 8 2}$ & 0.27 \\
\hline C1 - School closing & $\mathbf{0 . 8 1}$ & 0.44 \\
\hline C2 - Workplace closing & $\mathbf{0 . 8 1}$ & 0.41 \\
\hline C3 - Cancel public events & $\mathbf{0 . 7 9}$ & 0.51 \\
\hline C5 - Close public transport & $\mathbf{0 . 7 8}$ & 0.17 \\
\hline C4 - Restrictions on gatherings & $\mathbf{0 . 7 7}$ & 0.47 \\
\hline C8 - International travel controls & $\mathbf{0 . 7 1}$ & 0.46 \\
\hline E1 - Income support & 0.20 & $\mathbf{0 . 7 9}$ \\
\hline E2 - Debt/contract relief & 0.37 & $\mathbf{0 . 6 5}$ \\
\hline E3 - Fiscal measures & 0.10 & 0.06 \\
\hline
\end{tabular}

Source: own calculations in SPSS.

\section{Dynamic clusters and CMI}

Figure 4 visualises the selected loadings $(>0.5)$ between the two factors and the observed variables. Factor 1 seen in blue (F1) is loaded to $\mathrm{C} 1-\mathrm{C} 8$ (in the decreasing order from left) as described by Equation 1 and factor 2 (F2) is loaded to E1 and E2 as described by Equation 2.

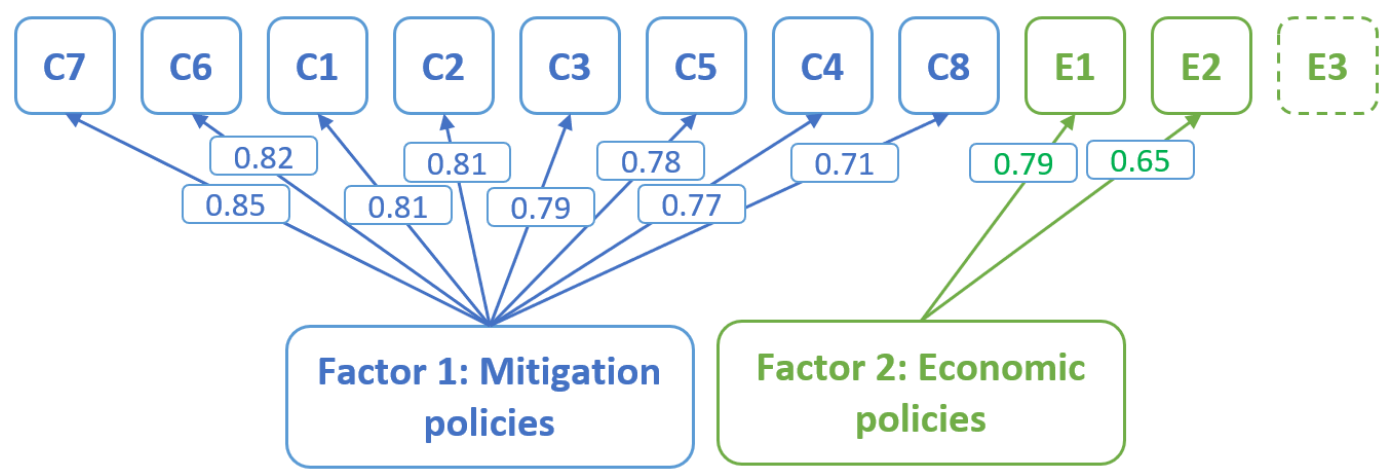

Figure 4. Factors are loaded to the observed variables Source: own visualisation.

The previous results are combined by considering the obtained clusters of the three periods and their average values of the CMI. The values of the average CMI of each cluster over the three periods are collected in Table 6.

On the left side of Figure 5 the nine clusters of the first period of January-February 2020 are shown. They are obtained by GMM similarly to the way they are shown for March-April 2020. We notice from Table 6 that cluster 1 has 97 countries with negligible policy measures (CMI=0.0096), while other clusters are smaller, having 1-28 countries.

Cluster 8 is formed by China alone with $\mathrm{CMI}=48.4$, which reflects the beginning of the pandemic in late 2019 already in China and its strict measures, while the second strictest measures were taken in cluster 5 with $\mathrm{CMI}=14.241$. Cluster 5 is composed of 11 countries including, e.g., early affected European countries such as Italy and Spain, large Asian countries such as India and Indonesia. 
Table 6. Dynamic clusters and average CMI values

\begin{tabular}{|c|c|c|c|c|c|c|}
\hline \multirow{2}{*}{ Variables } & \multicolumn{2}{|c|}{ January-February } & \multicolumn{2}{|c|}{ March-April } & \multicolumn{2}{|c|}{ June-July } \\
\hline & CMI & countries & CMI & countries & CMI & countries \\
\hline CL1_avg & 0.096 & 97 & 57.837 & 30 & 71.962 & 34 \\
\hline CL2_avg & 2.026 & 28 & 50.846 & 81 & 66.682 & 145 \\
\hline CL3_avg & 2.996 & 9 & 67.145 & 53 & & \\
\hline CL4_avg & 5.573 & 16 & 49.259 & 15 & & \\
\hline CL5_avg & 14.241 & 11 & & & & \\
\hline CL6_avg & 4.702 & 12 & & & & \\
\hline CL7_avg & 0.964 & 2 & & & & \\
\hline CL8_avg & 48.376 & 1 & & & & \\
\hline CL9_avg & 6.494 & 3 & & & & \\
\hline
\end{tabular}

Source: own calculations.

Other clusters have $\mathrm{CMI}<7$ suggesting very limited policy measures by the end of February 2020. However, the larger number of clusters imply very diverse stages and policy measures over the world countries.

As seen at the right side of Figure 5, in addition to mainland China of cluster 8, only Hong Kong (26.7) and Mongolia (25.3) obtain CMI $>25$ in the first period, and only six others (all in cluster 5 ) have CMI > 10, i.e., Macao (20.0 - not shown on the map), Vietnam (18.1), South Korea (15.5), Italy (14.3), Taiwan (13.1) and Indonesia (11.3). Other 18 countries have $5<\mathrm{CMI}<10.81$ out of the 179 countries have $\mathrm{CMI}=0.0$ and have not yet started any mitigation policies in practice.

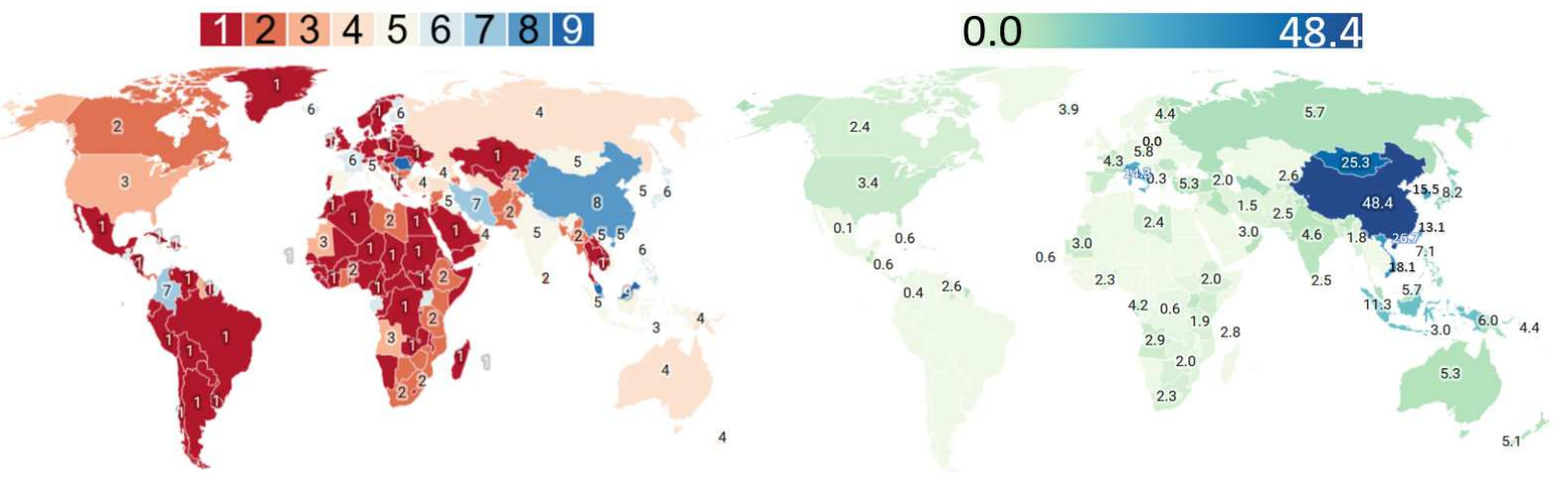

Figure 5. Nine clusters (left) and CMI (right) in the first period, January-February 2020 Source: own study.

The left side of Figure 6 shows the 4 clusters for the period March-April 2020 as was analysed previously. At this stage almost all world countries were hit by Covid-19. The cluster averages of CMI values range from 49.3 of cluster 4 with 15 countries including, e.g., the early hit Italy and China (the average is at the same level as CMI for China already in the first period, but now China's $\mathrm{CMI}=78.9$, while Italy's is as high as 87.4) to 67.1 of cluster 3 with 53 countries, including e.g., Spain (CMI=69.1) and India (CMI=76.6).

The right side of Figure 6 describes the CMIs. Totally 11 countries have CMI > 75: Italy (87.4), Iraq (80.2), China (78.9), Philippines (78.4), Palestine (77.9 - not shown on the map), France (77.8), India (76.6), San Marino (75.9 - not shown), Peru (75.3), Georgia (75.2), and Honduras (75.1). The other 124 countries have $50<\mathrm{CMI}<75$; 38 countries have $25<\mathrm{CMI}<50$; 5 countries have $0<\mathrm{CMI}<25$, while only Gibraltar (not shown) of United Kingdom has $\mathrm{CMI}=0.0$. 

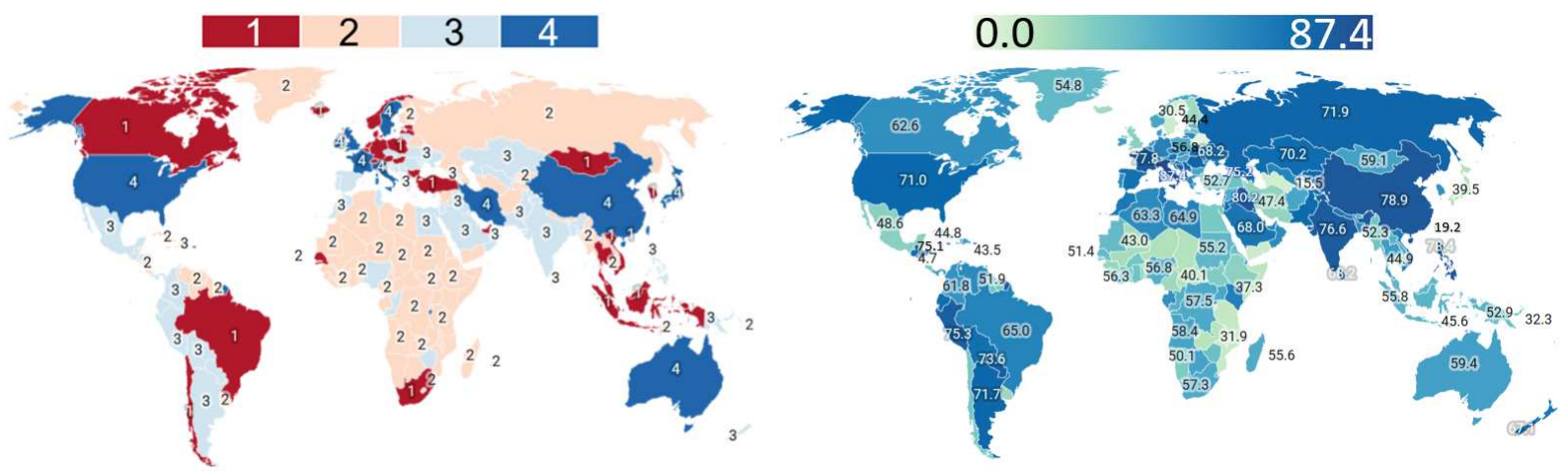

Figure 6. Four clusters (left) and CMI (right) in the second period, March-April 2020 Source: own study.

Figure 7 shows the two clusters for the period May-June. As seen on the left side of Figure 7, the small number of clusters imply convergence in Covid-mitigation policies. The peak of the first cycle of the pandemic has been passed in most of the world countries and mitigation policies are, however, strict on average: cluster 1 of 34 countries has $\mathrm{CMI}=72.0$ and cluster 2 has $\mathrm{CMI}=66.7$.

As seen on the right side of Figure 7, Honduras obtains the highest $\mathrm{CMI}=100.0$ followed by its neighbouring countries: El Salvador (96.1) and Guatemala (95.5). The next 75 countries, topped by Kenya (93.5), have $75<\mathrm{CMI}<95 ; 71$ countries have $50<\mathrm{CMI}<75 ; 27$ countries have $25<\mathrm{CMI}<50$, while the lowest CMIs are found in Gibraltar (0.0 - not shown on the map), Nicaragua (0.7), Belarus (11.1), Taiwan (18.1) and Turkmenistan (20.1) of which only Taiwan's low CMI is due to the Covid situation under control in May-June 2020.
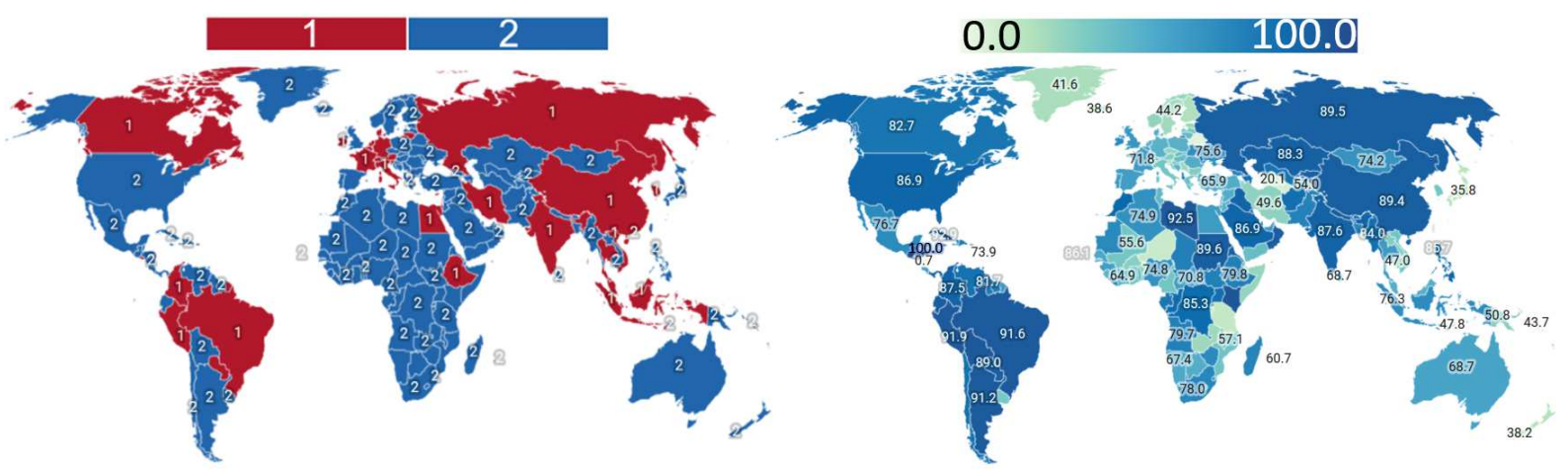

Figure 7. Two clusters (left) and CMI (right) in the third period, May-June 2020 Source: own study.

\section{CONCLUSIONS}

In this article, a dynamic clustering approach was introduced as a reply to the first research question to identify the country clusters and their development over time; the second research question on comparing the countries and their clusters was tackled with a new composite index. The study included most of the world countries (179). The multi-model approach of Gaussian Mixture Models, GMMs, was used for clustering and the Factor Analysis with Principal Axis Factoring, FA-PAF, was used to construct a composite mitigation index, $\mathrm{CMI}$, to help compare the clusters and individual countries by their policies. The six-month research period from January to June 2020 covered most of the first wave of the Covid-19 pandemic. This was further divided into three two-month-long sub-periods, the optimal number of clusters was obtained by GMM, and the CMI values for all the countries and each period were computed based on the factor analysis. The FA-PAF method was further able to recognize two factors: the actual mitigation factor and the economic support factor. 
The main finding of the study, in line with Hale et al. (2020a) and Kinnunen et al. (2020), include the detected decreasing optimal number of clusters, beginning with nine, decreasing to four, and ending up with only two clusters over the three sub-periods of the study. This implies that the government strategies converged over the time, i.e., the variation of mitigation policies decreased. At the same time, the policy measures strengthened (cf. Hale et al., 2020a) when compared by cluster averages of $\mathrm{CMI}$ although for individual countries, $\mathrm{CMI}$ could decrease, specifically in the last sub-period due to the enhanced situation at the end of the first wave of the Covid-19 pandemic.

The approach provides a big picture for policy makers as well as business decision-makers by offering a new method which describes the policy environment and its development over time with a daily updated policy database of the Oxford Covid-19 Government Response Tracker allowing close to real-time updates and monitoring of the governmental mitigation policies. The methods were described and applied to world countries and the key results were visualised. There are several ways how the governmental or industry actors may utilise the results and the presented approach. Policy makers can directly benefit by identifying the reference groups/clusters of their countries with comparable strategies to mitigate Covid-19, while supporting the societies economically, and to other country clusters where they may preferably belong. Depending on the policy-makers' attitudes towards, for example, suppressing (i.e., mitigating) the spreading of the coronavirus and the economic consequences of these policies, an analysis can be extended, even out of the scope of this article, to healthcare-related measures, such as (cumulative) daily infected citizens, number of patients in intensive care, healthcare capacity limitations and death tolls, and their trends together with economic measures, such as decreases in economic production, trade or numbers of foreign visitors and increases in unemployment or bankruptcies in various sectors of the economy, and apply multicriteria optimisation together with the introduced CMI to support the strategy formulation with respect to a preferred outcome in comparison with a selected reference group of countries.

With the relatively large dataset like ours, the probabilistic GMM approach can be seen robust. However, methodological comparative study, e.g., with fuzzy clustering methods, could be useful specifically because many border-line countries may have high probabilities of belonging to a cluster different than that country is assigned to. A semi-automated software/system including such optional features for a user to select from a straightforward application of the presented ideas could be easily built. This may allow further choosing of other lengths of periods than the two-month periods of this study. Similarly, different composite indices, such as PCA-based, in addition to our FA-PAF-based index construction, could be included in the close-to-real-time monitoring system, which should also allow a larger set of variables. A more detailed analysis is suggested. The dataset was restricted to mitigation policies, which are specifically set up to hinder or stop the spreading of the virus, and economic support policies to help economies and households get over the pandemic when income generation is a restricted side-effect of the mitigation policies.

\section{REFERENCES}

Andersen, N., Bramness, J.G., \& Lund, I.O. (2020). The emerging COVID-19 research: dynamic and regularly updated science mapsand analyses. BMC Medical Informatics and Decision Making, 20(1), 1-7. https://doi.org/10.1186/s12911-020-01321-9

Androniceanu, A. (2020). Major structural changes in the EU policies due to the problems and risks caused by COVID-19. Administratie si Management Public, 34, 137-149. https://doi.org/10.24818/amp/2020.34-08

Androniceanu, A., Kinnunen, J., \& Georgescu, I. (2020). E-Government clusters in the EU based on the Gaussian Mixture Models. Administratie si Management Public, 35, 6-20. https://doi.org /10.24818/amp/2020.35-01

Androniceanu, A., \& Marton, D.- M., (2021). The psychosocial impact of the Romanian government measures on the population during the COVID-19 pandemic. Central European Public Administration Review, 19(1), 7-32.

Androniceanu, A.-M., Georgescu, I., Dobrin, C., \& Dragulanescu I.V. (2020a). Multifactorial components analysis of the renewable energy sector in the OECD countries and managerial implications. Polish Journal of Management Studies, 22 (2), 36-49. https://doi.org/10.17512/pjms.2020.22.2.03 
Androniceanu, A.-M., Georgescu, I., Tvaronavičiene, M., \& Androniceanu, A.(2020b). Canonical Correlation Analysis and a New Composite Index on Digitalization and Labor Force in the Context of the Industrial Revolution 4.0. Sustainability, 12(17), 6812. https://doi.org/10.3390/su12176812

Biernacki, G., Celeux, G., \& Govaert, G. (2000). Assessing a mixture model for clustering with the integrated completed likelihood. IEEE Transactions on Pattern Analysis and Machine Intelligence, 22(7), 719-725. https://doi.org/10.1109/34.865189

Bouveyron, C., Celeux, G., Murphy, T.B., \& Raftery, A.E. (2019). Model-based clustering and classification for data science. Cambridge University Press.

Carrasco Sierra, A., Cobos Flores, M.J., Fuentes Duarte, B., \& Hernández Comi, B.I. (2020). Successful Management System by a Metalworking Mexican Company During Covid-19 Situation. Analysis Through a New Index (Case Study). International Journal of Entrepreneurial Knowledge, 8(2), 42-55. https://doi.org/10.37335 /ijek.v8i2.116

Celeux, G., \& Govaert, G. (1995). Gaussian parsimonious clustering models. Pattern Recognition, 28(5), 781-93. https://doi.org/10.1016/0031-3203(94)00125-6

Cheng, C., Barceló, J., Hartnett, A.S., Kubinec, R., \& Messerschmidt, L. (2020). COVID-19 government response event dataset (CoronaNet v. 1.0). Nature Human Behaviour, 4(7), 756-768. https://doi.org/10.1038/s41562020-0909-7

Davulis, T., Gasparènienè, L., \& Raistenskis, E. (2021). Assessment of the situation concerning psychological support to the public and business in the extreme conditions: case of Covid-19. Entrepreneurship and Sustainability Issues, 8(3), 308-322. https://doi.org/10.9770/jesi.2021.8.3(19)

Fabrigar, L.R., Wegener, D.T., Maccallum, R.C., \& Strahan, E.J. (1999). The use of exploratory factor analysis in psychological research. Psychological Methods, 4(3), 272-299. https://doi.org/10.1037/1082-989X.4.3.272

Fetzer, T.R., Witte, M., Hensel, L., Jachimowicz, J., Haushofer, J., Ivchenko, A., Caria, S., Reutskaya, E., Roth, C.P., Fiorin, S., Gómez, M., Kraft-Todd, G., Götz, F.M., \& Yoeli, E. (2020). Global behaviors and perceptions at the onset of the COVID-19 pandemic (No. w27082). National Bureau of Economic Research.

Hale, T., Petherick, A., Phillips, T., \& Webster, S. (2020a). Variation in government responses to COVID-19. Blavatnik School of Government Working Paper, 31, 2020-11.

Hale, T., Webster, S., Petherick, A., Phillips, T., \& Kira, B. (2020b). Stringency Index (OXBS). Oxford COVID-19 Government Response Tracker. Blavatnik School of Government Working Paper. Retrieved from https://www.bsg.ox.ac.uk/research/research-projects/oxford-covid-19-government-response-tracker on February 20, 2021.

Haleem, A., Javaid, M., \& Vaishya, R. (2020). Effects of COVID-19 pandemic in daily life. Current Medicine Research and Practice, 78-79. https://doi.org/10.1016/j.cmrp.2020.03.011

James, N., \& Menzies, M. (2020). Cluster-based dual evolution for multivariate time series: Analyzing COVID-19. Chaos: An Interdisciplinary Journal of Nonlinear Science, 30(6), 061108. https://doi.org/10.1063/5.0013156

Joliffe, I.T. (2002). Principal component analysis. Springer. 2nd edition

Kinnunen, J., \& Georgescu, I. (2020). Disruptive pandemic as a driver towards digital coaching in OECD countries. Revista Românească pentru Educaţie Multidimensională, 12(2Sup1), 55-61. https://doi.org/10.18662/rrem/12.2Sup1/289

Kinnunen, J., Georgescu, I., \& Androniceanu, A.-M. (2020). Evaluating governmental responses to Covid-19 and the implications for tourism industry. In Proceedings of 14th International Management Conference: Managing Sustainable Organizations, Bucharest, Romania, (pp. 585-594). https://doi.org/10.24818/IMC/2020/03.11

Kosach, I., Duka, A., Starchenko, G., Myhaylovska, O., \& Zhavoronok, A. (2020). Socioeconomic viability of public management in the context of European integration processes. Administratie si Management Public, 35, 139-152. https://doi.org/10.24818/amp/2020.35-09

Marona, B., \& Tomal, M. (2020). The COVID-19 pandemic impact upon housing brokers' workflow and their clients' attitude: Real estate market in Krakow. Entrepreneurial Business and Economics Review, 8(4), $221-232$. https://doi.org/10.15678/EBER.2020.080412

McLachlan, G., \& Peel, D. (2000). Finite mixture models. Wiley Series in Probability and Statistics. John Wiley \& Sons, Inc. 
Mollenkopf, D.A., Ozanne, L.K., \& Stolze, H.J. (2020). A transformative supply chain response to COVID-19. Journal of Service Management, ahead-of-print. https://doi.org/10.1108/JOSM-05-2020-0143

Moyo, N. (2020). Antecendents of employee disengagement amid COVID-19 pandemic. Polish Journal of Management Studies, 22(1), 323-334. https://doi.org/10.17512/pjms.2020.22.1.21

Nowiński, W., Haddoud, M., Wach, K., \& Schaefer, R. (2020). Perceived public support and entrepreneurship attitudes: A little reciprocity can go a long way! Journal of Vocational Behavior, 121, 103474. https://doi.org/10.1016/j.jvb.2020.103474

Pantano, E., Pizzi, G., Scarpi, D., \& Dennis, C. (2020). Competing during a pandemic? Retailers' ups and downs during the COVID-19 outbreak. Journal of Business Research, 116, 209-213. https://doi.org/10.1016/j.jbusres.2020.05.036

Rahman, M.A., Zaman, N., Asyhari, A.T., Al-Turjman, F., Bhuiyan, M.Z.A., \& Zolkipli, M.F. (2020). Data-driven dynamic clustering framework for mitigating the adverse economic impact of Covid-19 lockdown practices. Sustainable Cities and Society, 62, 102372. https://doi.org /10.1016/j.scs.2020.102372

Sawangchai, A., Prasarnkarn, H., Kasuma, J., Polyakova, A.G., \& Qasim, S. (2020). Effects of COVID-19 on digital learning of entrepreneurs. Polish Journal of Management Studies, 22(2), 502-517. https://doi.org/10.17512/pjms.2020.22.2.33

Wach, K., \& Bilan, S. (2021). Public support and administration barriers towards entrepreneurial intentions of students in Poland. Administratie si Management Public, 36(1).

Zandi, G., Shahzad, I., Farrukh, M., \& Kot, S. (2020). Supporting role of society and firms to COVID-19 management among medical practitioners. International Journal of Environmental Research and Public Health, 17(21), 12. 7961. https://doi.org/10.3390/ijerph17217961

Zarikas, V., Poulopoulos, S.G., Gareiou, Z., \& Zervas, E. (2020). Clustering analysis of countries using the COVID19 cases dataset. Data in Brief, 31, 105787. https://doi.org/10.1016/j.dib.2020.105787 


\section{Authors}

The contribution share of authors is equal and amounted to $25 \%$ for each of them.

\section{Jani Kinnunen}

Doctoral Researcher at Information Systems, Åbo Akademi, Turku, Finland. His research interests include public policy analytics, machine learning, fuzzy modelling, and investment analysis.

Correspondence to: Jani Kinnunen, Savitehtaankatu 2 A 4, 20540, Turku, Finland, email: jani.kinnunen@abo.fi ORCID (1) http://orcid.org/0000-0002-0154-6617

\section{Irina Georgescu}

PhD Lecturer at Department of Informatics and Economic Cybernetics (Bucharest University of Economic Studies, Bucharest, Romania). Her research interests include time series analysis and data mining applications.

Correspondence to: Irina Georgescu, PhD, Bucharest University of Economics, Calea Dorobantilor 15-17, Sector 1, Bucharest, 010552, Romania, e-mail: irina.georgescu@csie.ase.ro

ORCID (1) http://orcid.org/0000-0002-8536-5636

\section{Zahra Hosseini}

PhD in Educational Technology (2013, University of Malaya, Kuala Lumpur, Malaysia); PhD researcher in Communication and Media Department, Tampere University, Finland; Her research interests include TPACK, technology integration into teaching and learning, Technology Acceptance Models.

Correspondence to: Dr Zahra Hosseini, Tampere University, Kalevantie 4, 33100 Tampere, Finland, email: zahra.hosseini@tuni.fi

ORCID ㄴ) http://orcid.org/0000-0003-0423-8529

\section{Ane-Mari Androniceanu}

PhD Student at the Management Doctoral School, Bucharest University of Economic Studies, Bucharest, Romania. Her research interests include: economic growth, digitalisation, circular economy, international business and entrepreneurship.

Correspondence to: ane.androniceanu.drd@gmail.com

ORCID (1) http://orcid.org/0000-0002-1441-4496

\section{Conflict of Interest}

The authors declare that the research was conducted in the absence of any commercial or financial relationships that could be construed as a potential conflict of interest.

\section{Copyright and License}

This article is published under the terms of the Creative Commons

Attribution - NoDerivs (CC BY-ND 4.0) License

http://creativecommons.org/licenses/by-nd/4.0/ 